\title{
The accuracy of cone-beam computed tomography and augmented fluoroscopy-guided bronchoscopic marking of multiple small-sized pulmonary nodules in a hybrid operating room: a retrospective cohort study
}

\author{
Takashi Anayama ${ }^{1,2 \#}$, Marino Yamamoto ${ }^{1 \#}$, Kentaro Hirohashi ${ }^{1}$, Ryohei Miyazaki ${ }^{1}$, Hironobu Okada ${ }^{1}$, \\ Akinori Doi ${ }^{3}$, Kazumasa Orihashi ${ }^{4}$ \\ ${ }^{1}$ Department of Thoracic Surgery, Kochi Medical School, Kochi University, Kochi, Japan; ${ }^{2}$ Department of Photodynamic Therapy, Kochi Medical \\ School Hospital, Kochi University, Kochi, Japan; ${ }^{3}$ Department of Radiology, Kochi Medical School Hospital, Kochi, Japan; ${ }^{4}$ Department of Surgery \\ II, Kochi Medical School, Kochi University, Kochi, Japan
}

\#These authors contributed equally to this work.

Correspondence to: Dr. Takashi Anayama. Department of Thoracic Surgery, Kochi Medical School, Kochi University, Kohasu Okocho Nankoku, Kochi 781-5108, Japan. Email: anayamat@kochi-u.ac.jp.

Background: For the minimally invasive excision of small-sized pulmonary nodules, bronchoscopic markings are increasingly being performed owing to advancements in video-assisted thoracic surgery (VATS). Hybrid operating room equipment is utilized for bronchoscopic VATS markings. We aimed to compare the marking accuracy between bronchoscopic VATS and other marking techniques such as computed tomography-guided percutaneous marking and conventional X-ray fluoroscopy-guided bronchoscopic marking.

Methods: Patients with small-sized pulmonary nodules scheduled to undergo VATS were enrolled in the study. A mixture of 50 to $100 \mu \mathrm{L}$ of diluted indocyanine green and iopamidol was injected adjacent to the pulmonary nodules as a VATS marker. Patients receiving each of the three image-guided techniques were categorized into group A (computed tomography-guided percutaneous injection), group B (X-ray fluoroscopy-guided virtual bronchoscopy-assisted bronchoscope injection), and group C (cone-beam computed tomography and augmented fluoroscopy-guided virtual bronchoscope-assisted bronchoscopic injection in the hybrid operating room). VATS marking accuracy and procedural complications were compared among the three groups.

Results: In total, 61 patients with 73 pulmonary nodules were eligible for analysis. VATS marking was successful for 15/16 nodules in group A, 28/30 nodules in group B, and 25/27 nodules in group C. Marking accuracy was $5.75 \pm 4.59,15.00 \pm 14.02$, and $6.05 \pm 6.11(\mathrm{~mm})$, respectively. Multiple markings were successful in 0/1 (0\%), 5/6 (83.3\%), and 5/5 (100.0\%) nodules in groups A, B, and C, respectively. A small pneumothorax occurred in $3 / 15(20.0 \%)$ patients in group A.

Conclusions: The cone-beam computed tomography and augmented fluoroscopy-guided bronchoscopic approach performed in a hybrid operating room is accurate and equivalent to the computed tomographyguided percutaneous approach, and it enables the VATS marking of multiple pulmonary nodules without causing a secondary pneumothorax.

Keywords: Bronchoscopic marking; cone-beam computed tomography; hybrid operating room; minimally invasive surgery; small-sized pulmonary nodules

Submitted Jun 20, 2020. Accepted for publication Sep 30, 2020.

doi: $10.21037 /$ qims-20-781

View this article at: http://dx.doi.org/10.21037/qims-20-781 


\section{Introduction}

Computed tomography (CT) is currently the most effective screening method for detecting lung cancer and reducing lung cancer mortality (1-3). The pulmonary lesion, radiologically called a ground-glass nodule (GGN), is suggestive of lung adenocarcinoma of the following histological subtypes: adenocarcinoma in situ (AIS) and minimally invasive adenocarcinoma (MIA) (4). Since AIS and MIA are classified as non-invasive, early-stage lung cancers, they are considered to be a good indication for limited pulmonary resection (5-9). Furthermore, small-sized pulmonary metastases from other malignancies could also be an indication for limited pulmonary resection as a part of a multidisciplinary treatment approach (10-15). However, some of the small-sized pulmonary nodules, such as GGNs, and metastatic pulmonary nodules are hard to identify during video-assisted thoracic surgery (VATS), unless there are accompanying visceral pleural changes such as pleural indentation. A VATS marker placement, therefore, is considered prior to surgery.

Preoperative CT-guided hookwire placement has been the most commonly used method to localize small-sized pulmonary lesions. VATS markers such as a hook-thread (16), spiral wire needle (17), microcoil (18), fiducial markers (19), color dyes such as methylene blue (20), barium (21), and lipiodol (22), and radiotracers such as technetium 99 and Tc $99 \mathrm{~m}(23,24)$ are placed nearby the target pulmonary lesions. Pneumothorax, hemothorax, or air embolus can occur because of the invasive puncture of the visceral pleura.

Bronchoscopic marking is an alternative to a percutaneous approach. VATS markers are delivered nearby the target pulmonary nodules through the accessory channel of the flexible bronchoscope. If properly performed, bronchoscopic marking of the pulmonary nodules is achieved without injuring the visceral pleura and, therefore, avoiding the risk of pneumothorax. Various materials such as methylene blue (25), indigo carmine (26), and fiducial markers (27) have been used as materials for bronchoscopic VATS markings. Generally, X-ray fluoroscopy is used in combination with bronchoscopy to reach the peripheral lung lesion. However, if the target pulmonary nodule is not clearly visible on X-ray fluoroscopy, it is not easy to lead the VATS marker to the vicinity of the target, which could lower the VATS marking accuracy. Recently, ENB has been used to increase the accuracy of bronchoscopic VATS markings. By registering the previously obtained CT data, the bronchoscope can be guided to the vicinity of the peripheral lung mass, which is not visible on $\mathrm{X}$-ray fluoroscopy $(25,28-30)$.

The cone-beam CT (CBCT)-guided bronchoscopy performed in hybrid operating rooms (ORs) may be useful in improving the accuracy of bronchoscopic markings. However, it is unclear how the accuracy of the procedure will be improved by adding the imaging guidance available in the hybrid OR to that used during conventional bronchoscopic marking. In this historical controlled study, we aimed to numerically clarify how the latest image-guided technology improves the accuracy of markings compared to that obtained with conventional X-ray fluoroscopic image-guided bronchoscopy. We hypothesize that the utilization of the hybrid OR can improve the accuracy of the bronchoscopic markings. This will become widely recognized and used in clinical practice.

In the current study, three different VATS marking approaches were compared: CT-guided percutaneous VATS marking, X-ray fluoroscopy-guided bronchoscopic VATS marking, and bronchoscopic VATS marking in a hybrid OR.

We have completed the ICMJE uniform disclosure form (available at http://dx.doi.org/10.21037/qims-20-781).

\section{Methods}

\section{Ethics, consent, and permissions}

Patients provided written informed consent to participate in the study and for individual patient data to be published. This study was approved by the institutional review board of Kochi Medical School, Kochi University, and registered in the Japanese clinical trial registration database (registration number: UMIN-CTR R000027833), which is accepted by the International Committee of Medical Journal Editors.

\section{Eligible participants}

Patients who were scheduled to undergo VATS wedge resection of a non-solid, partly solid, or solid pulmonary nodule with a maximum nodule diameter of less than 20 $\mathrm{mm}$ and without radiological changes in the visceral pleura on CT located in the peripheral lung (outer $1 / 3$ side of the lung) were included in this study. The study period was from January 2013 to December 2014 for CT-guided percutaneous marking, January 2015 to December 2016 for navigation bronchoscopic marking, and January 2017 to December 2018 for CBCT and augmented fluoroscopyguided bronchoscopic marking in the hybrid OR. The study 


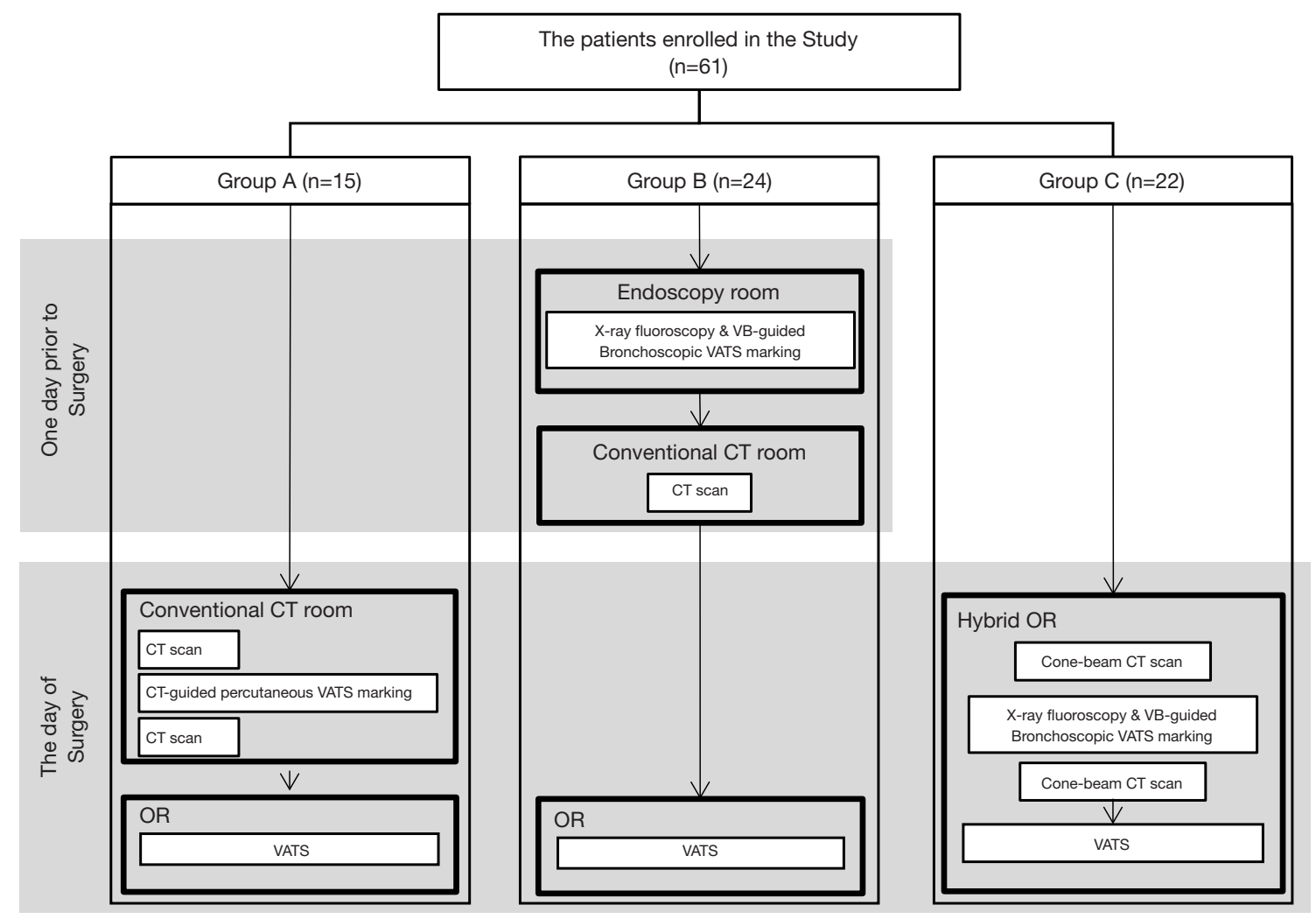

Figure 1 The flow of video-assisted thoracic surgery (VATS) marking procedures in each group. In group A, CT-guided percutaneous VATS markings are performed on the morning of surgery. The patients are moved from the CT room to the operating room (OR) for VATS. In group B, bronchoscopic VATS markings are performed in the endoscopy room on the day prior to surgery using X-ray fluoroscopy and virtual bronchoscopic navigation. After the procedure, the patient is moved to the CT room, and a CT scan is performed to confirm the VATS marker placement. In group C, patients are given general anesthesia in the hybrid OR; all subsequent procedures, including cone-beam computed tomography (CBCT) (registration of the target lesion), bronchoscopic VATS markings with imaging guidance by augmented X-ray fluoroscopy, and another CBCT to confirm the successful VATS marking, are performed simultaneously.

design for all periods is illustrated in Figure 1.

\section{Group A: CT-guided percutaneous marking}

The CT-guided percutaneous marking procedure was performed from January 2013 until December 2014 as previously reported (31).

The patient was placed in either the prone, supine, or lateral position, depending on the location of the lesion. After a preliminary scan, the CT scanner (320-row area detector CT, Aquilion ONE; Canon Medical Systems Co., Ltd., Tochigi, Japan) was focused on the area of the pulmonary nodule. After providing local anesthesia with lidocaine, a 23-gauge needle filled with the marking solution was inserted near the pulmonary nodule. Fifty to
$100 \mu \mathrm{L}$ of indocyanine green (ICG)/iopamidol marking solution was injected during real-time imaging using CT fluoroscopy (Figure 2).

\section{Group B: X-ray fluoroscopy-guided bronchoscopic marking}

The bronchoscopic marking procedure was performed from January 2015 until May 2017 as previously reported (31).

After local anesthesia had been performed, moderate sedation was achieved by administrating $2-3 \mathrm{mg}$ of midazolam intravenously. A thin, flexible bronchoscope (Olympus P290; Olympus, Tokyo, Japan) was inserted nasally into the tracheobronchial tree. The bronchoscope was led from the subsegmental bronchus to the target pulmonary nodule under virtual bronchoscopy navigation 

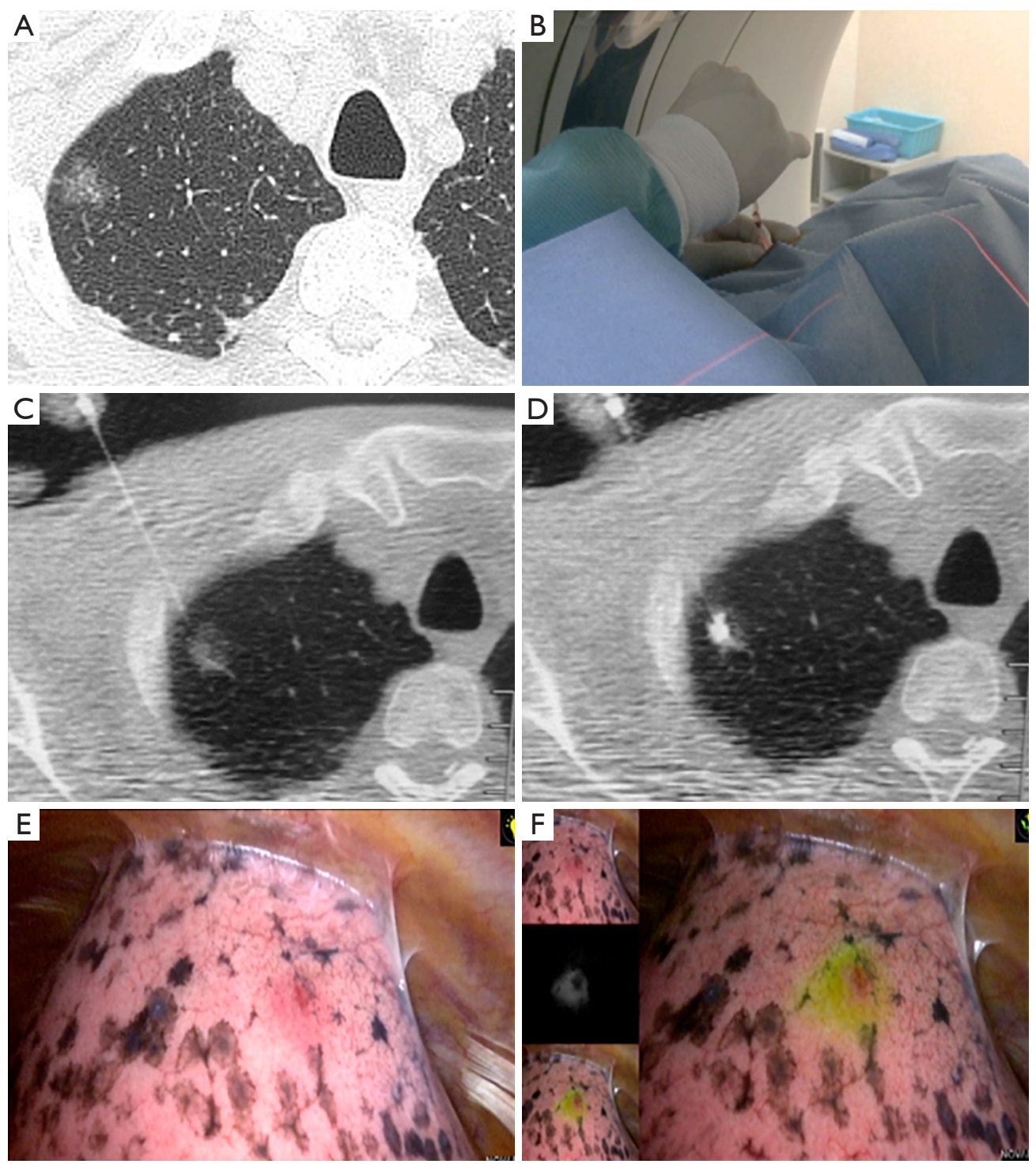

Figure 2 CT-guided percutaneous marking. (A) A localized ground-glass nodule visualized using CT. (B) Puncture using a 23-G needle under local anesthesia. (C) Needle puncture near the target during apnea. (D) Injection of $0.05 \mathrm{~mL}$ of indocyanine green (ICG)/iopamidol mixed solution serving as a video-assisted thoracic surgery (VATS) marker. (E) White-light imaging by thoracoscopy. (F) ICG fluorescence (ICG-FL) imaging showing the ICG-FL marker as a green spot.

generated by the CT DICOM data with the Synapse Vincent (Fuji Film, Tokyo, Japan) volume analyzer.

A bronchoscopic biopsy needle was inserted through the accessory channel of the flexible bronchoscope to the peripheral aspect of the bronchus immediately below the visceral pleura under $\mathrm{X}$-ray fluoroscopy. The sheath was retracted $3 \mathrm{~cm}$ from that position, the transbronchial aspiration cytology (TBAC) needle was exposed $1 \mathrm{~cm}$ from the sheath, and then, the sheath and the needle were advanced together
$1 \mathrm{~cm}$ to puncture the lung parenchyma. Fifty to $100 \mu \mathrm{L}$ of ICG/iopamidol marking solution was injected into the lung parenchyma under X-ray fluoroscopy. A chest CT was then performed to confirm the marking point (Figure 3).

\section{Group C: CBCT and augmented X-ray fluoroscopy-guided bronchoscopic VATS marking in the hybrid OR}

Group C included 22 consecutive patients who undertook 

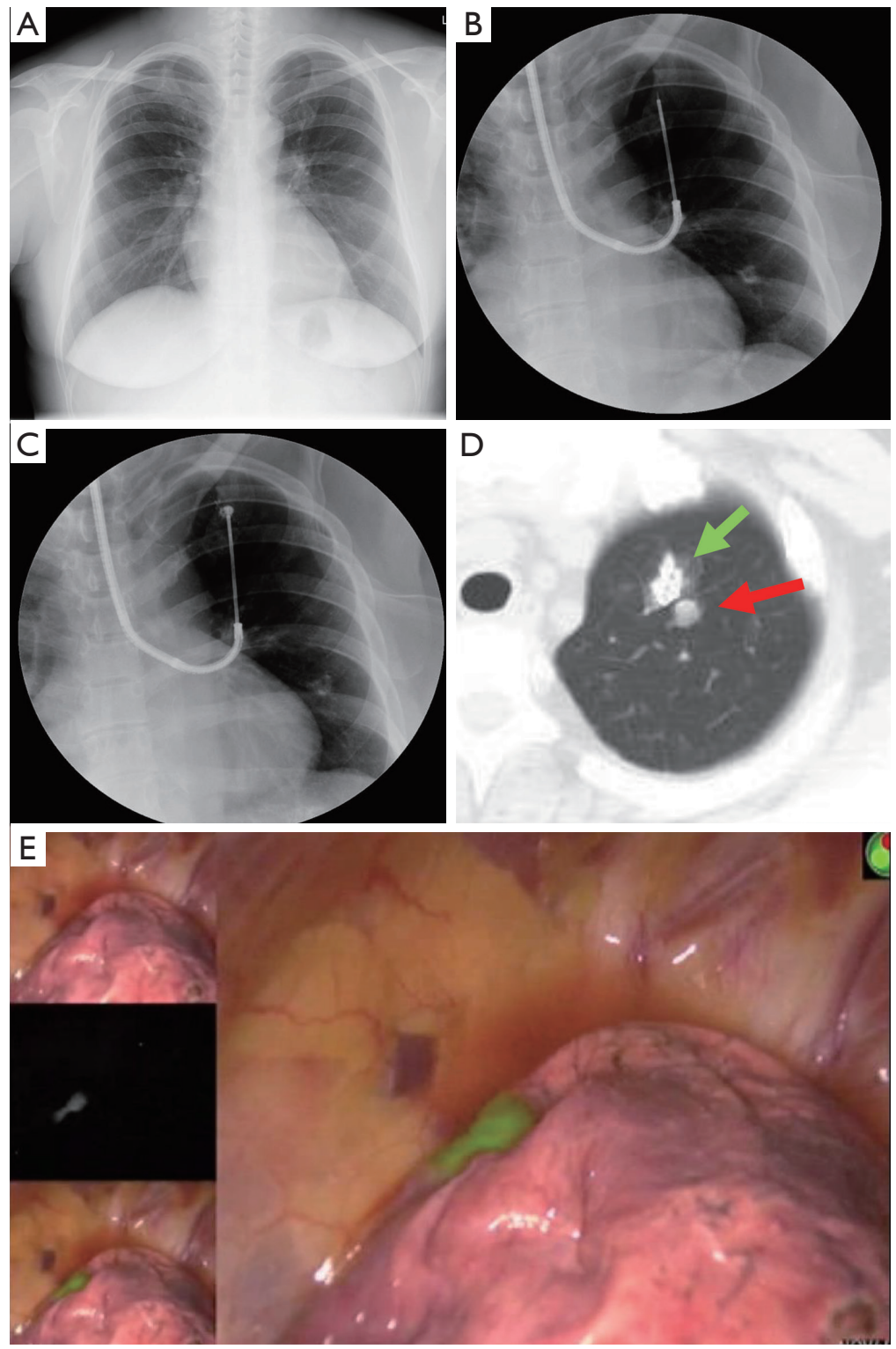

Figure 3 Bronchoscopic marking with conventional X-ray fluoroscopy and virtual bronchoscopy guidance. (A) A tumor on the left apex of the lung is not visualized on a plain chest X-ray. (B) A bronchoscopic needle is led under radioscopy and virtual bronchoscopy to the site where the tumor is considered to be present. (C) Injection of video-assisted thoracic surgery (VATS) marker. (D) After the bronchoscopy is complete, patients are moved to the CT room, a CT scan is performed, and the positional relationship between the target lesion (red arrow) and the VATS marker (green arrow) is confirmed. (E) Visualization of indocyanine green fluorescence by fluorescent thoracoscopy.

CBCT and navigation bronchoscopic VATS marking.

The patient was given general anesthesia in the hybrid $\mathrm{OR}$, and tracheal intubation was performed. Non-contrast CBCT was performed during suspended respiration using an Artis Q device (Siemens Healthcare, Forchheim, Germany). Cross-sectional images were then reconstructed automatically on a dedicated workstation (Syngo X
Workplace; Siemens Healthcare, Forchheim, Germany). On cross-sectional images, the target lesion was manually contoured in multiple orthogonal planes using dedicated software (Syngo iGuide Toolbox; Siemens Healthcare, Forchheim, Germany). The contours were displayed live on augmented X-ray fluoroscopy for intraprocedural guidance. A bronchoscope was then inserted through the tracheal 
tube to the peripheral bronchus. A TBAC needle-guide sheath was led close to the target pulmonary nodule under CBCT-augmented X-ray fluoroscopy guidance. When the TBAC needle was deployed nearby the target contour, the C-arm of the CBCT-augmented X-ray fluoroscopy was tilted from the vertical to the horizontal direction to confirm that the tip of the TBAC needle was placed at the appropriate position three-dimensionally (Figure $4 A, B$ ). The VATS marker was then injected into the parenchyma near the target pulmonary lesion in the same manner as that performed in group B (Figure 4C,D). Compared to the first CBCT taken at the beginning of the procedure (Figure $5 A$ ), the second CBCT (Figure 5B,C) confirmed that the bronchoscopically injected VATS marker is located adjacent to the target pulmonary lesion. A three-dimensional CT image displaying the target pulmonary nodule(s) and VATS marker(s) in the half-translucent lung was created for intraoperative reference aiding the surgeons (Figure $5 D)$. After inserting a bronchial blocker for isolated lung ventilation, the patient was placed in a lateral position, and VATS was continued.

\section{ICG fluorescence (ICG-FL) VATS marker}

An ICG/iopamidol mixture was prepared as a VATS marker solution by diluting ICG $(2.5 \mathrm{mg} / \mathrm{mL}, 10 \mathrm{~mL}$; DaiichiSankyo, Tokyo, Japan) 100-fold with iopamidol (Iopamiron 370; Bayer, Leverkusen, Germany). A 1-mL syringe was filled with the ICG/iopamidol mixture and connected to either a 23-gauge CT-guided percutaneous needle or a 21-gauge bronchoscopic biopsy needle (NA-1C-1; Olympus America). The needle lumen was filled with the marking solution prior to the marking procedure.

\section{Examination of VATS marking accuracy}

The straight-line distance connecting the center points of both the VATS marker and the target lung mass was measured on the CT workstation (Figure $5 A, B, C$ ). The primary outcome was set as the marking accuracy (i.e., the straight-line distance between a target pulmonary nodule and the corresponding VATS marker), and the secondary outcomes were defined as the detection rate of fluorescent VATS markers and the incidence of adverse events.

\section{ICG-FL-guided thoracoscopic wedge resection}

Three-dimensional CT images of the half-translucent lung including the pulmonary nodule(s) and VATS marker(s) were displayed side-by-side with a thoracoscopy display during surgery to clarify the positional relationship between the marker and the tumor (Figure 5D). The ICG-FL VATS marker was visualized by the PINPOINT ${ }^{\circledR}$ endoscopic fluorescence imaging system (Stryker, Kalamazoo, MI) (Figure 2E,F, Figure 4D). The part of the lung thought to contain the tumor was partially excised with an endo-stapler. Successful removal was confirmed by rapid pathological diagnosis.

\section{Statistical analyses}

Any significant differences in the continuous variables among the categorized groups were compared using the Kruskal-Wallis test. Fisher's exact test was used for the comparison of discrete variables between groups.

The required sample size for group $\mathrm{C}$ was determined as follows. Previous research comparing the marking accuracy between group A (pulmonary nodules $\mathrm{n}=15$ ) and group B $(n=25)$ revealed that group A was more accurate than group $\mathrm{B}(\mathrm{P}=0.0012$, power $=0.830)$. Therefore, $\mathrm{P}<0.05$ and power $=0.8$ were defined for the setting of the current study. The effect size was defined as 0.8 according to custom.

To negate the null hypothesis that there is no significant difference in marking accuracy between group B and group $\mathrm{C}$ under the above-defined conditions, the required sample size of group $\mathrm{C}$ was $\mathrm{n}=19$. The $a$ priori power analysis to determine the sample size for the nonparametric dataset was calculated using $\mathrm{G}^{*}$ power version 3.1.9.2 (a program written by Franz Faul, University of Kiel, Germany). All other statistical analyses were performed using JMP version 14 (SAS, Cary, NC, USA).

\section{Results}

In total, 61 patients participated in this clinical trial, including 15 patients in group A (CT-guided percutaneous marking), 24 patients in group B (X-ray fluoroscopy-guided bronchoscopic marking), and 22 patients in group C (CBCT and augmented $\mathrm{X}$-ray fluoroscopy-guided bronchoscopic marking). Clinical background data and the results of each patient group are summarized in Table 1.

Group A included 15 patients with 16 pulmonary nodules who underwent VATS markings. ICG-FL was successfully detected by near infra-red spectroscopy (NIRS) thoracoscopy in 15/16 (93.8\%) pulmonary nodules (Table 2). In a patient with two pulmonary nodules, VATS marking 

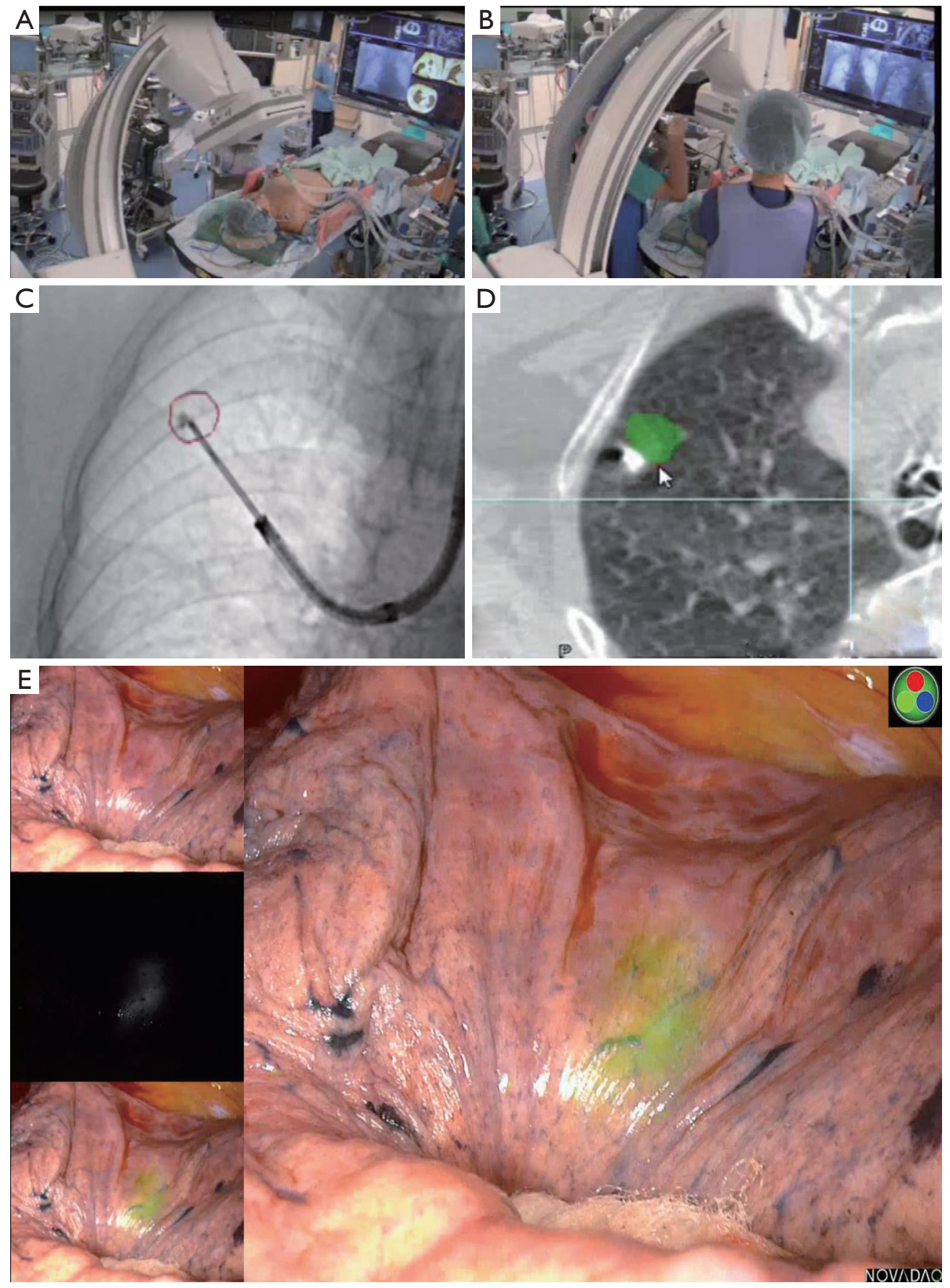

Figure 4 Bronchoscopic video-assisted thoracic surgery (VATS) marking in the hybrid operating room (OR). (A) After the induction of general anesthesia, the target lesion can be visualized using cone-beam CT (CBCT); the tumor can then be displayed as red nodules or circles on augmented fluoroscopy. Even if the tumor itself is not visible under radiography, the position of the target lesion can be indicated on the monitor throughout the procedure. (B) A flexible bronchoscope is inserted through the intratracheal tube to the peripheral bronchus. The tip of the bronchoscopic needle is guided to the target lesion under both augmented X-ray fluorography and virtual bronchoscopy guidance. (C) A total of $0.05 \mathrm{~mL}$ of a VATS marker is injected. (D) A CBCT scan is performed again to confirm that the VATS marker was injected adjacent to the target pulmonary nodule (green-colored lesion). (E) The patient is repositioned into the lateral recumbent position. Thoracoscopic surgery is started, and the position of the target lesion is visualized using fluorescent thoracoscopy. 

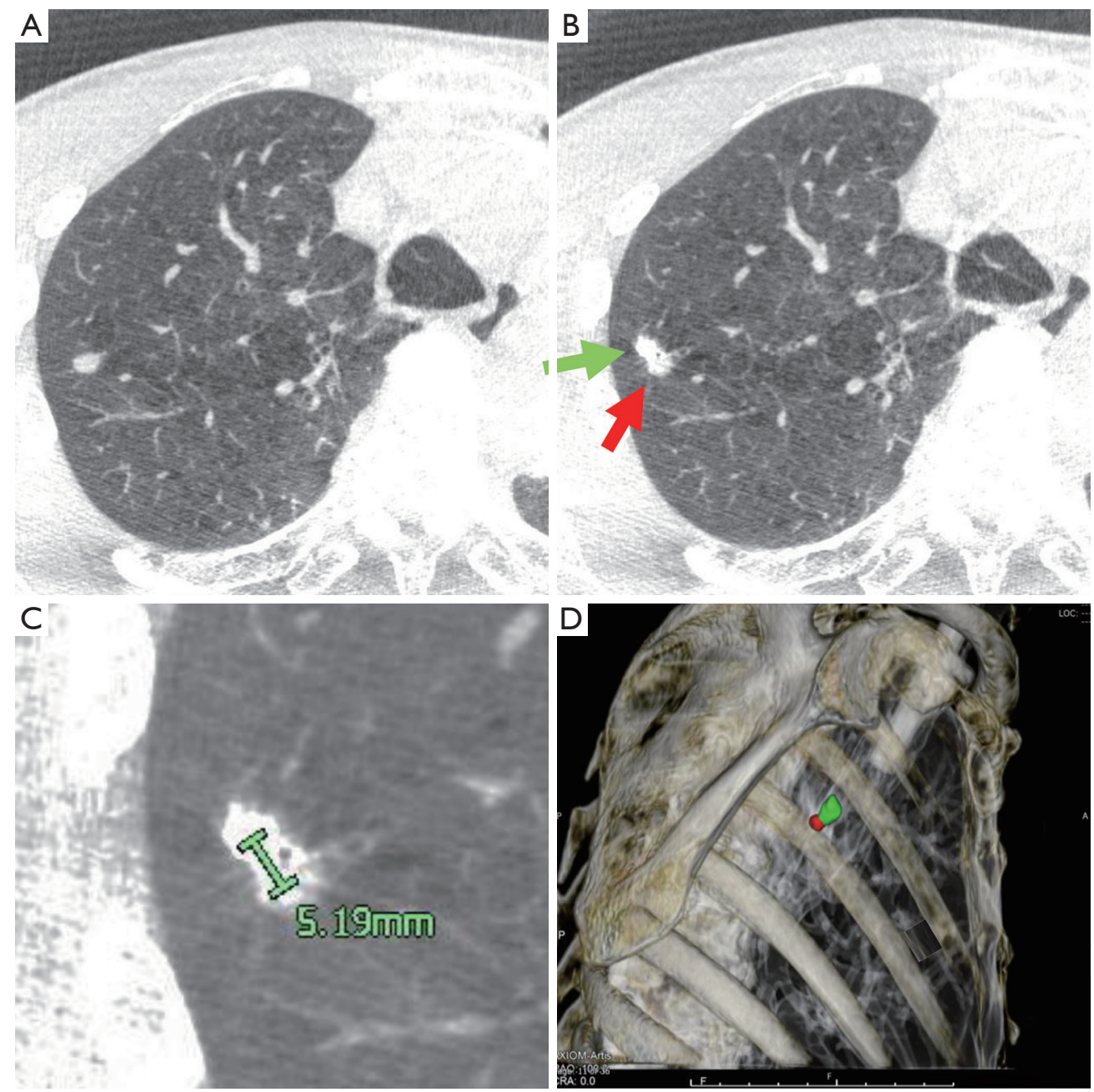

Figure 5 Examination of the accuracy of VATS marking on CT images. (A) The target pulmonary nodule to be marked by VATS. (B) CT image after the VATS marker (green arrow) is injected near the target pulmonary nodule (red arrow). (C) The distance between the center point of the target lesion and the center point of the VATS marker is measured on the workstation. (D) Three-dimensional chest image from the right lateral direction. The surgeon confirms that the VATS maker (green spot) is placed near the target (red spot).

was attempted for the second nodule and failed because of the development of a small secondary pneumothorax that occurred after the first VATS marking. In total, a small pneumothorax occurred in $3 / 15(20.0 \%)$ patients in this group, none of whom required a chest tube insertion.

Group B included 24 patients with 30 nodules. The first and second VATS markings were successful in 28/30 $(93.3 \%)$ and $5 / 6(83.3 \%)$ pulmonary nodules, respectively (Table 2).

In group C, we required at least 19 pulmonary lesions with successful VATS markings that could be evaluated for accuracy by measuring the distance between the tumor and the marker. Assuming a marking success rate of $80 \%$,
24 lesions were required. Thus, 25 consecutive pulmonary nodules with successful VATS markings were included in group C. VATS markings were successful for the first 20/22 pulmonary nodules. In the two unsuccessful cases, the ICGFL VATS marker was placed deeper into the lesion in the lung parenchyma, $22 \mathrm{~mm}$ from the visceral pleura; hence, the NIRS thoracoscope failed to visualize the ICG-FL intraoperatively. Markings of the second $(n=3)$ and third nodules $(\mathrm{n}=2)$ were all successful.

For pulmonary nodules in which the ICG-FL VATS marker was not detected by the NIRS thoracoscope, the access portal was extended by about $3 \mathrm{~cm}$, and the surgeon localized the pulmonary nodules by finger palpation. 
Table 1 Patient demographics, pathological information, and radiological findings of pulmonary nodules

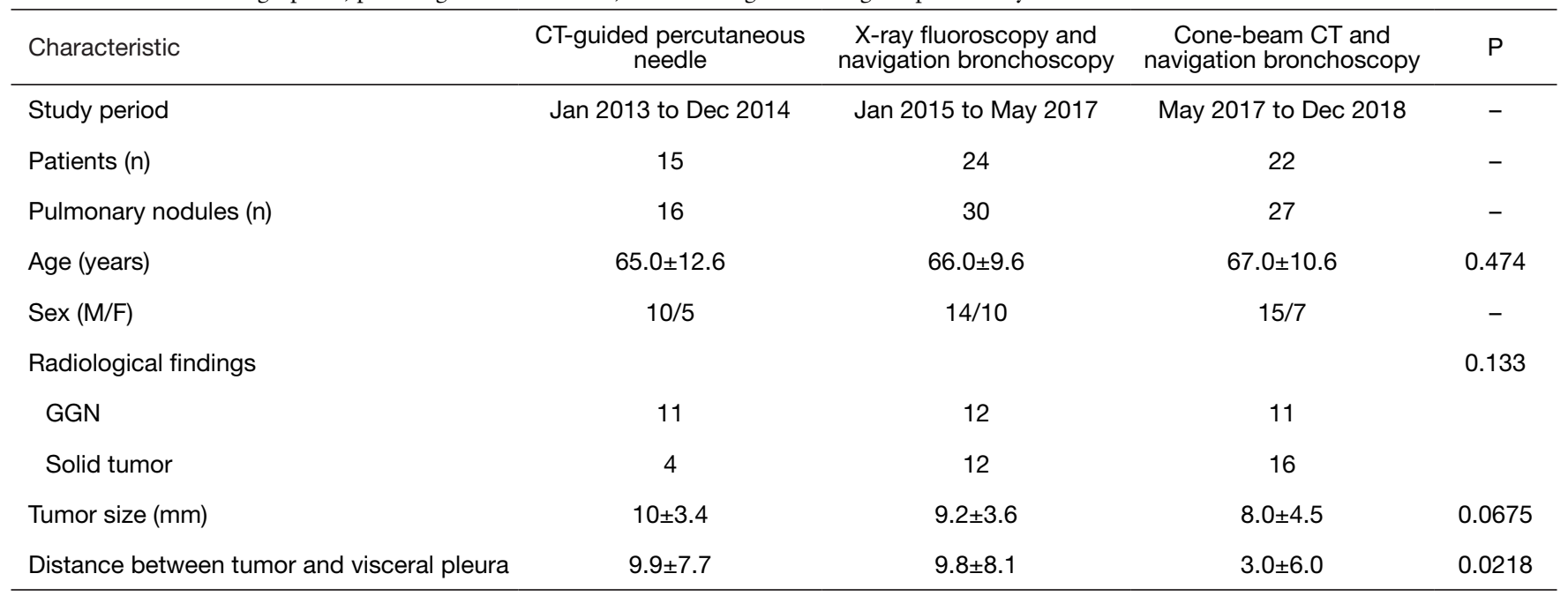

Fisher's exact probability test was used for comparison of discrete variables between groups. The Kruskal-Wallis test was used to test differences in continuous variables between groups. GGN, ground-glass nodule; CT, computed tomography.

Table 2 Results of each VATS marking approach

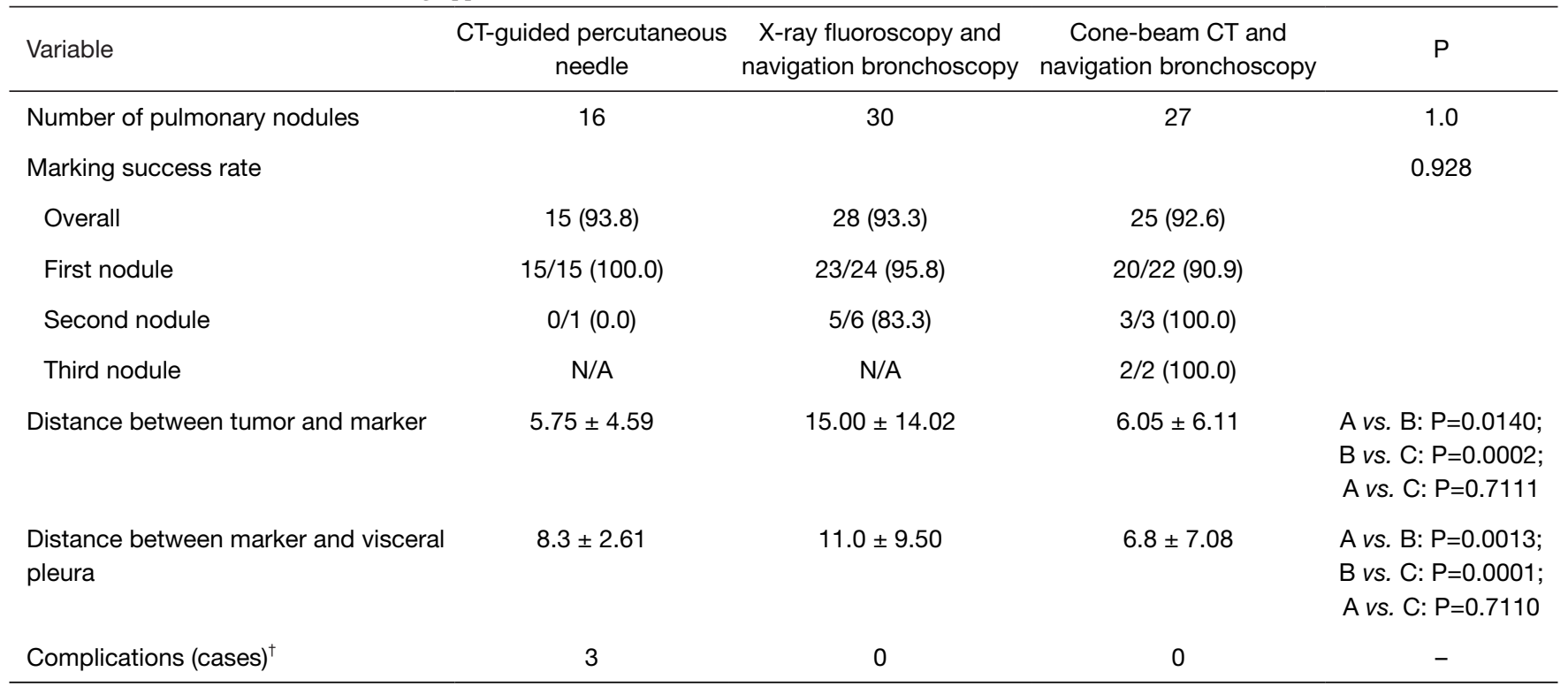

The denominator is the total number of the target pulmonary nodules, and the numerator is the number of successful VATS markings. Values in parentheses are percentages. Fisher's exact probability test was used to compare discrete variables between groups. The Kruskal-Wallis test was used to compare continuous variables between groups. ${ }^{\dagger}$, minor secondary pneumothorax was observed in 3 cases in group A. VATS, video-assisted thoracic surgery; CT, computed tomography.

Ultimately, the target pulmonary nodules were successfully resected with a negative surgical margin in all patients. Other than a small pneumothorax in three patients in group A, no complications were observed throughout the study period.

\section{Discussion}

In this study, three VATS marking techniques were compared in terms of the accuracy and complication rate. The image-guided bronchoscope in the hybrid OR was more accurate than the bronchoscopic marking under 
normal radiography and was comparable to CT-guided percutaneous marking. The results of the current study proved that CBCT and augmented X-ray fluoroscopic imaging navigation can improve the accuracy of the bronchoscopic approach to peripheral pulmonary nodules. With this technique, bronchoscopic VATS marking can be performed with the same accuracy as the conventional percutaneous approach, but with fewer complications. This technique could be implemented in clinical practice to detect and resect small and/or multiple pulmonary nodules with accuracy, while avoiding complications. This result indicates that the hybrid OR is useful as a helpful imageguided modality in reaching a peripheral lung target by bronchoscopy. It is hoped that the hybrid OR will be used not only for the purpose of bronchoscopic VATS marking but also for all bronchoscopy procedures for peripheral pulmonary lesions.

In group A, CT-guided percutaneous needle marking was performed while observing the target in real-time, and the approaching route was independent of the bronchial anatomy, thus, the marking accuracy was naturally high. On the other hand, since a small pneumothorax developed when the visceral pleura was punctured, this method was not suitable for repeated VATS markings at multiple locations. There are some anatomical points of the lung where the scapula or ribs interfere, the apex of the lung near the subclavian artery or vein, or the deep mediastinal aspect of the lung where percutaneous VATS marking would not be suitable.

Groups B and C had VATS markings performed with a TBAC needle inserted through the accessory channel of the flexible bronchoscope. This method is suitable for multiple VATS markings because it minimally damages the visceral pleura, reducing the risk of pneumothorax. From the central bronchus to the middle layer, virtual bronchoscopy navigation can guide the tip of the bronchoscope through the correct central bronchus, leading to the peripheral bronchus where the target peripheral pulmonary nodule is located. Bronchoscopic guidance in the middle to the peripheral bronchus is done exclusively by $\mathrm{X}$-ray fluoroscopy. This is considered to be the main factor that reduces the accuracy of the marking in this group. Small lung masses and GGNs may have been unclear on the fluoroscopy images used in Group B.

Group $\mathrm{C}$ first underwent a CBCT scan, and the threedimensional location of the small pulmonary mass lesion that was invisible by simple radiography was registered. Even if target lesions such as GGNs are not visible on
X-ray fluoroscopic images, the target lesion can be virtually displayed on the augmented X-ray fluoroscopic image based on the CBCT data. X-ray fluoroscopy accompanying CBCT is also used during bronchoscope insertion, but small lung lesions are virtually displayed on radiographs taken in anterior-posterior or side views. Therefore, the tip of the TBAC needle can be accurately guided to the lesion. This is the main factor that improved the marking accuracy in group C. In group C, since CT imaging and VATS markings are performed under general anesthesia, there is no subject movement, thus, ensuring accuracy. Patients do not suffer any pain due to the general anesthesia.

\section{Limitations}

In this study, there was no difference in the VATS marking accuracy between group A and group C, but if the larger sample size is considered, group $\mathrm{C}$ may be less accurate than group A. This is because group C may be affected by the superiority of bronchoscopic procedures. However, group $\mathrm{C}$ still has the advantage of being able to mark multiple points with fewer incidences. The effectiveness of group C's method should be verified by testing the inter-operator reliability in a multicenter study.

\section{Conclusions}

VATS marking under bronchoscopy with a CBCT and augmented $\mathrm{X}$-ray fluoroscopy guide under general anesthesia in a hybrid OR may have an accuracy comparable to CT-guided percutaneous VATS marking. By utilizing the tools of the hybrid OR, the accuracy of approaching and marking the peripheral target lesion by the use of a bronchoscope can be increased to a level that is comparable to that achieved by a CT-guided approach. The utilization of hybrid ORs for bronchoscopy/interventions is expected to increase in more facilities.

\section{Acknowledgments}

Funding: This work was financially supported by a Grant-inAid for Scientific Research KAKENHI from the Japanese Society for the Promotion of Science (grant number JP15K01294).

\section{Footnote}

Conflicts of Interest: All authors have completed the ICMJE 
uniform disclosure form (available at http://dx.doi. org/10.21037/qims-20-781). The authors have no conflicts of interest to declare.

Ethical Statement: This study was approved by the institutional review board of Kochi Medical School, Kochi University, and registered in the Japanese clinical trial registration database (registration number: UMINCTR R000027833), which is accepted by the International Committee of Medical Journal Editors. Patients provided written informed consent to participate in the study and for individual patient data to be published.

Open Access Statement: This is an Open Access article distributed in accordance with the Creative Commons Attribution-NonCommercial-NoDerivs 4.0 International License (CC BY-NC-ND 4.0), which permits the noncommercial replication and distribution of the article with the strict proviso that no changes or edits are made and the original work is properly cited (including links to both the formal publication through the relevant DOI and the license). See: https://creativecommons.org/licenses/by-nc-nd/4.0/.

\section{References}

1. National Lung Screening Trial Research Team, Aberle DR, Adams AM, Berg CD, Black WC, Clapp JD, Fagerstrom RM, Gareen IF, Gatsonis C, Marcus PM, Sicks JD. Reduced lung-cancer mortality with low-dose computed tomographic screening. N Engl J Med 2011;365:395-409.

2. National Lung Screening Trial Research Team, Church TR, Black WC, Aberle DR, Berg CD, Clingan KL, Duan F, Fagerstrom RM, Gareen IF, Gierada DS, Jones GC, Mahon I, Marcus PM, Sicks JD, Jain A, Baum S. Results of initial low-dose computed tomographic screening for lung cancer. N Engl J Med 2013;368:1980-91.

3. Moyer VA. Screening for lung cancer: U.S. preventive services task force recommendation statement. Ann Intern Med 2014;160:330-8.

4. Goldstraw P, Chansky K, Crowley J, Rami-Porta R, Asamura H, Eberhardt WEE, Nicholsin AG, Groome P, Mitchell A, Bolejack V. The IASLC lung cancer staging project: proposals for revision of the TNM stage groupings in the forthcoming (eighth) edition of the TNM classification for lung cancer. J Thorac Oncol 2016;11:39-51.

5. Yamato $Y$, Tsuchida $M$, Watanabe T, Aoki T, Koizumi N, Umezu H, Hayashi J. Early results of a prospective study of limited resection for bronchioloalveolar adenocarcinoma of the lung. Ann Thorac Surg 2001;71:971-4.

6. Koike T, Yamato Y, Yoshiya K, Shimoyama T, Suzuki R. Intentional limited pulmonary resection for peripheral T1 N0 M0 small-sized lung cancer. J Thorac Cardiovasc Surg 2003;125:924-8.

7. Yoshida J, Nagai K, Yokose T, Nishimura M, Kakinuma R, Ohmatsu H, Nishiwaki Y. Limited resection trial for pulmonary ground-glass opacity nodules: Fifty-case experience. J Thorac Cardiovasc Surg 2005;129:991-6.

8. Suzuki K, Koike T, Asakawa T, Kusumoto M, Asamura H, Nagai K, Tada H, Mitsudomi T, Tsuboi M, Shibata T, Fukuda H, Kato H, Japan Lung Cancer Surgical Study Group (JCOG LCSSG). A prospective radiological study of thin-section computed tomography to predict pathological noninvasiveness in peripheral clinical IA lung cancer (Japan Clinical Oncology Group 0201). J Thorac Oncol 2011;6:751-6.

9. Yendamuri S, Sharma R, Demmy M, Groman A, Hennon M, Dexter E, Nwogu C, Miller A, Demmy T. Temporal trends in outcomes following sublobar and lobar resections for small $(\leq 2 \mathrm{~cm})$ non-small cell lung cancers-a Surveillance Epidemiology End Results database analysis. J Surg Res 2013;183:27-32.

10. Headrick JR, Miller DL, Nagorney DM, Allen MS, Deschamps C, Trastek VF, Pairolero PC. Surgical treatment of hepatic and pulmonary metastases from colon cancer. Ann Thorac Surg 2001;71:975-9.

11. Ki EY, Lee KH, Park JS, Hur SY. A clinicopathological review of pulmonary metastasis from uterine cervical cancer. Cancer Res Treat 2016;48:266-72.

12. Petrella F, Diotti C, Rimessi A, Spaggiari L. Pulmonary metastasectomy: an overview. J Thorac Dis 2017;9:S1291-8.

13. Anile M, Mantovani S, Pecoraro Y, Carillo C, Gherzi L, Pagini A, Rendina EA, Venuta F, Diso D. Pulmonary metastasectomy in uterine malignancies: outcome and prognostic factors. J Thorac Dis 2017;9:S1273-7.

14. Zellweger M, Abdelnour-Berchtold E, Krueger T, Ris HB, Perentes JY, Gonzalez M. Surgical treatment of pulmonary metastasis in colorectal cancer patients: Current practice and results. Crit Rev Oncol Hematol 2018;127:105-16.

15. Kumar NAN, Verma K, Shinde RS, Kammar P, Dusane R, Desouza A, Ostwal V, Patil P, Engineer R, Karimundackal G, Pramesh CS, Saklani A. Pulmonary metastasectomy of colorectal cancer origin: Evaluating process and outcomes. J Surg Oncol 2018;118:1292-300.

16. Gossot D, Miaux Y, Guermazi A, Celerier M, Friga J. The 
hook-wire technique for localization of pulmonary nodules during thoracoscopic resection. Chest 1994;105:1467-9.

17. Torre M, Ferraroli GM, Vanzulli A, Fieschi S. A new safe and stable spiral wire needle for thoracoscopic resection of lung nodules. Chest 2004;125:2289-93.

18. Lizza N, Eucher P, Haxhe JP, De Wispelaere JF, Johnson PM, Delaunois L. Thoracoscopic resection of pulmonary nodules after computed tomographic-guided coil labeling. Ann Thorac Surg 2001;71:986-8.

19. Sancheti MS, Lee R, Ahmed SU, Pickens A, Fernandez FG, Small WC, Nour SG, Force SD. Percutaneous fiducial localization for thoracoscopic wedge resection of small pulmonary nodules. Ann Thorac Surg 2014;97:1914-8.

20. Lenglinger FX, Schwarz CD, Artmann W. Localization of pulmonary nodules before thoracoscopic surgery: value of percutaneous staining with methylene blue. AJR Am J Roentgenol 1994;163:297-300.

21. Moon SW, Wang YP, Jo KH, Kwack MS, Kim SW, Kwon OK, Jang HS. Fluoroscopy-aided thoracoscopic resection of pulmonary nodule localized with contrast media. Ann Thorac Surg 1999;68:1815-20.

22. Watanabe K, Nomori H, Ohtsuka T, Kaji M, Naruke T, Suemasu K. Usefulness and complications of computed tomography-guided lipiodol marking for fluoroscopyassisted thoracoscopic resection of small pulmonary nodules: Experience with 174 nodules. J Thorac Cardiovasc Surg 2006;132:320-4.

23. Chella A, Lucchi M, Ambrogi MC, Menconi G, Melfi FM, Gonfiotti A, Boni G, Angeletti CA. A pilot study of the role of TC-99 radionuclide in localization of pulmonary nodular lesions for thoracoscopic resection. Eur J Cardiothorac Surg 2000;18:17-21.

24. Galetta D, Bellomi M, Grana C, Spaggiari L. Radioguided localization and resection of small or ill-defined pulmonary lesions. Ann Thorac Surg 2015;100:1175-80.

Cite this article as: Anayama T, Yamamoto M, Hirohashi K, Miyazaki R, Okada H, Doi A, Orihashi K. The accuracy of cone-beam computed tomography and augmented fluoroscopyguided bronchoscopic marking of multiple small-sized pulmonary nodules in a hybrid operating room: a retrospective cohort study. Quant Imaging Med Surg 2021;11(2):725-736. doi: 10.21037/qims-20-781
25. Bolton WD, Howe H 3rd, Stephenson JE. The utility of electromagnetic navigational bronchoscopy as a localization tool for robotic resection of small pulmonary nodules. Ann Thorac Surg 2014;98:471-5.

26. Sato M, Omasa M, Chen F, Sato T, Sonobe M, Bando T, Date H. Use of virtual assisted lung mapping (VAL-MAP), a bronchoscopic multispot dye-marking technique using virtual images, for precise navigation of thoracoscopic sublobar lung resection. J Thorac Cardiovasc Surg 2014;147:1813-9.

27. Anantham D, Feller-Kopman D, Shanmugham LN, Berman SM, DeCamp MM, Gangadharan SP, Eberhardt R, Herth F, Ernst A. Electromagnetic navigation bronchoscopy-guided fiducial placement for robotic stereotactic radiosurgery of lung tumors: a feasibility study. Chest 2007;132:930-5.

28. Anayama T, Qiu J, Chan H, Nakajima T, Weersink R, Daly M, McConnell J, Waddell T, Keshavjee S, Jaffray D, Irish JC, Hirohashi K, Wada H, Orihashi K, Yasufuku K. Localization of pulmonary nodules using navigation bronchoscope and a near-infrared fluorescence thoracoscope. Ann Thorac Surg 2015;99:224-30.

29. Awais O, Reidy MR, Mehta K, Bianco V, Gooding WE, Schuchert MJ, Luketich JD, Pennathur A. Electromagnetic navigation bronchoscopy-guided dye marking for thoracoscopic resection of pulmonary nodules. Ann Thorac Surg 2016;102:223-9.

30. Sullivan JL, Martin MG, Weksler B. Navigational bronchoscopy-guided dye marking to assist resection of a small lung nodule. J Vis Surg 2017;3:131.

31. Anayama T, Hirohashi K, Miyazaki R, Okada H, Kawamoto N, Yamamoto M, Sato T, Orihashi K. Nearinfrared dye marking for thoracoscopic resection of smallsized pulmonary nodules: comparison of percutaneous and bronchoscopic injection techniques. J Cardiothorac Surg 2018;13:5. 